\title{
A Study of Laboratory Bunsen Burners for Natural Gas
}

\author{
By John H. Eiseman
}

\begin{abstract}
Sixteen different laboratory-type Bunsen burners, sold as suitable for natural gas, were purchased and their limits of operation determined. Eight of the burners were of the Meker type, and eight were straight-tube burners. The results of the study indicate the need for certain changes in design if satisfactory operating characteristics are to be obtained with natural gas.

A comparison of the dimensions of these burners with the fundamental relations for good burner operation brought out the following three major reasons for their unsatisfactory performance: Too small a port area, improper throat size, and insufficient primary air opening. In addition to these three factors, use of the proper orifice size was also found to be of importance. Two burners, one a straight-tube and the other a Meker type, were modified so that they complied with the requirements as determined by this study. Both burners were found to be greatly improved and were capable of producing a hot, stable flame over a range of gas rates approximately double their former usable rates.
\end{abstract}

\section{Introduction}

Although the principle of the Bunsen burner has been known for many years, studies of the elements of design leading to the most effective application of this principle are comparatively recent. In 1921 the Bureau issued Technologic Paper $193[1],{ }^{1}$ the first American publication on this subject, and for nearly 10 years this was the only authoritative data available on the design of burners of the Bunsen type. Since 1931 additional data have been made available by the American Gas Association Testing Laboratories, the National Bureau of Standards, and others, but even today the literature on burner design is not extensive.

Most of the research work on burners has been done on those used in domestic appliances such as ranges, water heaters, central heating appliances, and space heaters. The manufacturers of these appliances are, in general, utilizing the basic design data now available, but many other types of burners on the market do not conform to the dimensions and proportions essential for the most satisfactory performance. The average laboratory Bunsen burner does not comply with these essen-

\footnotetext{
${ }_{1}^{1}$ Figures in brackets indicate the literature references at the end of this paper. Additional important papers not cited in the text are also given.
}

tial dimensions, and although for many heating operations with certain gases it gives satisfactory performance, there are other laboratory requirements which are not adequately met by these burners, particularly with natural and other slowburning gases.

In 1947 the gas supplied to Washington, D. C., was changed from a mixed manufactured and natural gas of $600 \mathrm{Btu} / \mathrm{ft}^{3}$ to a straight natural gas of approximately $1,100 \mathrm{Btu} / \mathrm{ft}^{3}{ }^{3} \mathrm{Up}$ to this time very little difficulty had been experienced with the various makes of laboratory burners, but since the change-over complaints have been the rule rather than the exception, even though all the burners currently in use were either converted for natural gas or replaced by new burners advertised as natural gas burners.

The average laboratory burner is inexpensive in comparison with most of the domestic or commercial burners. In most laboratories it is not used continuously and many of the heating applications for which it is used do not require any great range of adjustment. In fact in many cases a knowledge of the rate at which heat is delivered is unimportant. If the gas will ignite and continue to burn and not require too long a time to perform the desired heating operation, the burner is satis- 
factory. There are other uses, however, where it is necessary to supply gas at a definite and uniform rate with an adjustment that produces a hot stable flame. Most of the trouble experienced in the laboratories at this Bureau has been caused by a flame that is not stable when the rate is adjusted for the delivery of a sufficient number of heat units per hour to raise the material being heated to the desired temperature.

Even if it is known at what rate heat is required, there is little information available that would enable the purchaser to pick out the proper laboratory burner. The catalogs do not usually show the rates for which these laboratory burners are intended, and in some cases where such data are given the burners cannot be used at the indicated rates.

As a result of this lack of information regarding laboratory-type burners and because of failure to obtain satisfactory performance with any of the types on hand, a number of these burners were studied to determine the limits within which they could be used. It was hoped that a correlation of this information with the basic requirements for good burner design would bring out some of the reasons for the poor showing on natural gas and point the way to the changes required for satisfactory operation. Since the composition of the natural gas supply in Washington, D. C., is close to an average of that used in other parts of the country, the results should be equally applicable wherever natural gas is used.

\section{Burners Tested}

Sixteen different Bunsen-type burners, all advertised as suitable for natural gas, were selected from catalogs and purchased. Of these, eight are straight-tube burners and eight are of the Meker type. These burners are believed to be representative of those most commonly used in laboratory work, and the test results should, therefore, be indicative of the range of operation that can be obtained from laboratory burners in general.

Figure 1 shows the eight Meker burners and figure 2 the eight straight-tube burners tested. These photographs show the variations in size and design of typical laboratory burners. The straight- tube burners are composed of a base into which the orifice is mounted, a straight mixing-tube in which the gas and air are mixed, an opening for the air to enter the mixing tube, and a flame-retainer. The flame-retainer is merely an enlarged annular opening surrounding the main burner port. A small amount of the air-gas mixture is supplied to this annular ring by several small holes connecting it with the main supply in the mixing-tube. The small ring of flame thus formed around the main burner flame permits a greater range of adjustment of the burner without encountering unstable conditions. The orifices used in these burners are either of the fixed or adjustable type. The fixed orifice is, as its name implies, a fixed opening through which the gas passes. Any change in rate (at constant pressure) is made by removing the orifice and inserting one of a different size. The adjustable orifice is usually composed of a cap with a fixed opening and a tapered needle that can be moved in or out of this fixed hole, thereby changing its size.

Like the straight-tube burner, the Meker-type burner has a base, orifice, mixing-tube, air-opening, and burner-head, or port. It differs from the straight-tube burner in that the mixing-tube usually has a constriction, or venturi throat that increases the amount of air drawn into the burner, and the burner-head has a number of small ports in place of the single opening used with the straight-tube burner. The orifice may be either fixed or adjustable. In all of the 16 burners tested it was possible to vary the size of the opening through which room air entered the mixing-tube.

The numbers on the burners in figures 1 and 2 correspond to the burner numbers in table 1 . This table gives the type of burner, throat area, port area, and other dimensions of each burner, which will be discussed in connection with the basic design relations in section VIII.

In addition to testing the 16 commercial burners, an experimental burner was designed and built. This burner was used to determine whether certain fundamental relationships that had previously been established with respect to burners of domestic appliances were equally applicable to burners of the laboratory-type. 


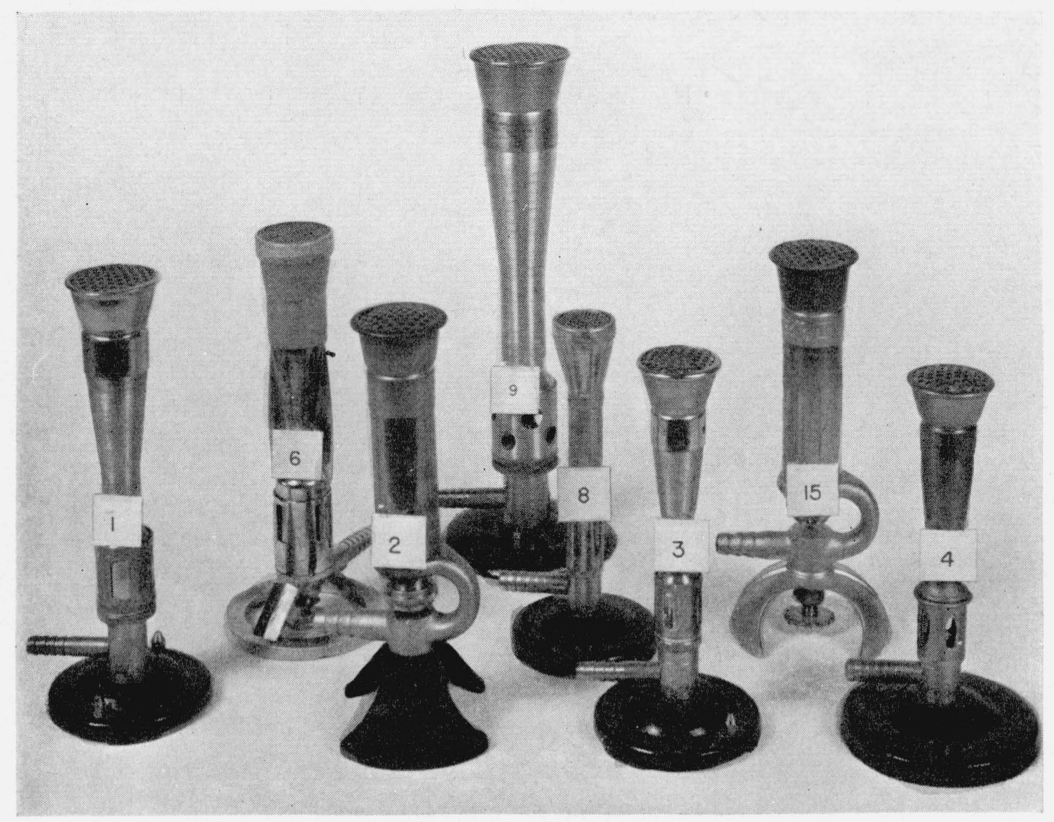

Figure 1. Laboratory burners tested. Meker type.

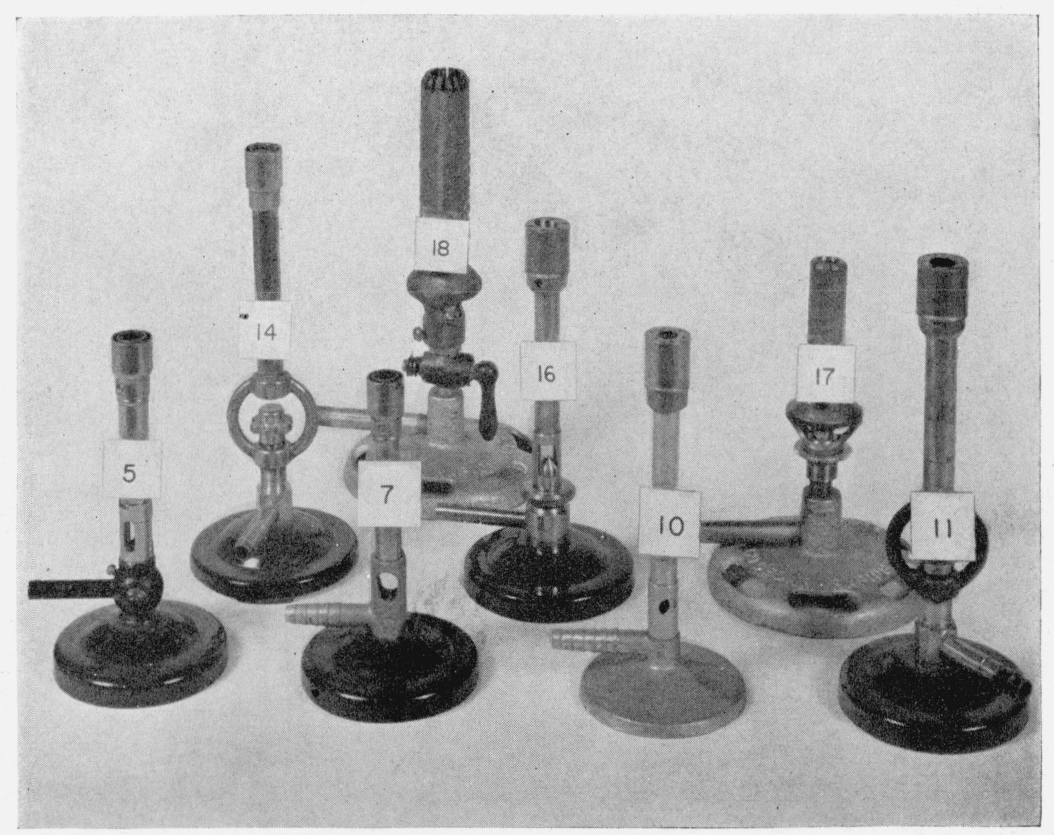

Figure 2. Laboratory burners tested. Straight-tube type. 
TABLE 1. List of burners tested, with dimensions of each

\begin{tabular}{|c|c|c|c|c|c|c|c|c|c|c|c|c|}
\hline $\begin{array}{l}\text { Burner } \\
\text { num- } \\
\text { ber }\end{array}$ & Type of burnez & $\begin{array}{l}\text { Port } \\
\text { area }\end{array}$ & $\begin{array}{c}\text { Throat } \\
\text { area }\end{array}$ & $\begin{array}{c}\text { Ratio } \\
\text { throat } \\
\text { port }\end{array}$ & $\begin{array}{l}\text { Air } \\
\text { shut- } \\
\text { ter } \\
\text { open- } \\
\text { ing }\end{array}$ & $\begin{array}{c}\begin{array}{c}\text { Ratio } \\
\text { air shutter }\end{array} \\
\text { port area }\end{array}$ & $\begin{array}{l}\text { Num- } \\
\text { ber of } \\
\text { ports }\end{array}$ & $\begin{array}{l}\text { Diam- } \\
\text { eter of } \\
\text { ports }\end{array}$ & $\begin{array}{c}\text { Height of } \\
\text { burner }\end{array}$ & $\begin{array}{l}\text { Length } \\
\text { of } \\
\text { mixing } \\
\text { tube }\end{array}$ & $\begin{array}{l}\text { Length } \\
\text { of mixing } \\
\text { tube and } \\
\text { burner } \\
\text { head }\end{array}$ & $\begin{array}{l}\text { Ori- } \\
\text { fices } \\
\text { used } \\
\text { (drill } \\
\text { size) }\end{array}$ \\
\hline 1.-- & Meker............... & $\begin{array}{r}\text { in. } .^{2} \\
0.773\end{array}$ & $\begin{array}{r}\text { in. }{ }^{2} \\
0.332\end{array}$ & 0.429 & $\begin{array}{r}\text { in. }{ }^{2} \\
1.094\end{array}$ & 1.42 & 63 & $\begin{array}{l}\text { in. } \\
0.125\end{array}$ & $\begin{array}{l}\text { in } \\
85 \%\end{array}$ & $4^{i n .}$ & ${ }_{5}^{i n .}$ & 54,56 \\
\hline $2 \ldots$ & 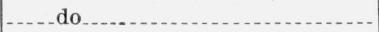 & .687 & .322 & .468 & 0.402 & 0.59 & 56 & .125 & 8 & $45 / 8$ & $55 \%$ & a 46 \\
\hline $3 \ldots$ & - $d o_{-}$ & .663 & .166 & .251 & .773 & 1.17 & 54 & .125 & $71 / 2$ & $33 / 16$ & $41 / 8$ & 60 \\
\hline $4 \ldots$ & - & .589 & .174 & .295 & .646 & 1. 10 & 48 & .125 & $71 / 4$ & $31 / 4$ & $41 / 8$ & 56 \\
\hline $5 \ldots$ & $\begin{array}{l}\text { Straight tube with stabilizer top b } \\
\text { and pilot. }\end{array}$ & .139 & .139 & 1. 000 & .414 & 2.98 & 1 & .420 & 6 & 358 & $35 \%$ & 57,68 \\
\hline $6 \ldots$ & Meker & '1. 019 & .302 & 0.296 & .936 & 0.92 & 155 & d. 08 & $81 / 2$ & $33 / 4$ & $4^{15 / 16}$ & 54,56 \\
\hline $7 \ldots$ & Straight tube with flame retainer $\mathrm{b}$ & 0.110 & .110 & 1. 000 & .163 & 1. 47 & 1 & .375 & $51 / 2$ & $31 / 2$ & $31 / 2$ & 69 \\
\hline $8 \ldots$ & Meker & .254 & .307 & 1. 207 & .807 & 3.18 & 121 & .052 & 7 & $23 / 4$ & $43 / 16$ & a 54 \\
\hline $9 \ldots$ & - $d 0_{0}$ & 1. 156 & .595 & 0.514 & 1. 366 & 1.18 & 98 & .125 & $107 / 8$ & $61 / 8$ & $71 / 4$ & 51 \\
\hline $10 \ldots$ & Straight tube with flame retainer ${ }^{\mathrm{b}}$ & 0.091 & .108 & 1. 184 & 0.161 & 1. 77 & 1 & .340 & $61 / 4$ & $3^{11 / 16}$ & $4^{3 / 8}$ & 52 \\
\hline $11 \ldots$ & ..... do b.... & .126 & .126 & 1.000 & .314 & 2.49 & 1 & .401 & $7^{11 / 16}$ & $33 / 4$ & $41 / 2$ & a 43 \\
\hline $14 \ldots$ & - do b $b$ - d & .139 & .139 & 1.000 & .462 & 3.33 & 1 & .420 & a $73 / 4-81 / 4$ & $4 \frac{3}{4}$ & $43 / 4$ & \& 51 \\
\hline $15 \ldots$ & Meker & .687 & .322 & 0.468 & .402 & 0.59 & 56 & .125 & $81 / 8$ & $45 \%$ & $5 \% / 8$ & a 46 \\
\hline $16 \ldots$ & Straight tube with flame retainer $b$ & .126 & .126 & 1.000 & .182 & 1. 44 & 1 & .401 & a $61 / 8-63 / 8$ & $3^{11} 1 / 16$ & $43 / 8$ & a 51 \\
\hline $17 \ldots$ & Straight tube & .113 & .174 & 1.537 & .368 & 3.26 & e 1 & e. 348 & $25^{15 / 16}-65 / 16$ & $21 / 2$ & $21 / 2$ & f 50 \\
\hline $18 \ldots$ & - & .296 & .363 & 1. 226 & .626 & 2.11 & g 1 & g. 580 & $85 / 16$ & 4 & 4 & f 45 \\
\hline
\end{tabular}

s Adjustable.

b Area of stabilizer or flame retainer not included as part of port area.

e 42-mm grid.

d Square ports.

- 12 slots, $0.05 \times 0.03$ in. each.

f Johnson adjustable.

g 16 slots, $0.05 \times 0.04$ in. each.

\section{Limits of Operation of a Laboratory Burner}

All burners of the Bunsen type are so designed that a portion of the air necessary for complete combustion mixes with the gas before it reaches the burner port, or ports. This "primary air" is injected into the burner by the momentum of the gas flowing from the orifice and enters the burner through the air openings located at the base of the mixing-tube. The additional air required is secured from the atmosphere surrounding the flame and is termed "secondary air." Gas of a definite composition requires a definite volume of air to burn each volume of gas, but the type of flame produced depends upon how much of the total air required is introduced as primary air. A low primary air causes a "lazy" flame, which is not sharply defined. As the primary air is increased the flame becomes smaller in volume and more clearly defined or "harder" in appearance. The same total heat is produced as long as the gas rate remains constant, but the higher the primary air the more concentrated this heat becomes. The usefulness of a burner for many purposes depends on the intensity of the flame, that is on the liberation of much heat in small volume [2]. For any given burner, however, there is a limit above which an increase in primary air causes the flame to become unstable and either lift away from the ports or flash back into the burner, depending upon the gas rate and the composition of the gas used. Natural gas gives very little trouble from flash-back but is particularly susceptible to lifting. Similarly, if the primary air is decreased, a limit is reached below which the color of the tip of the inner cone becomes yellow. This results from the formation of finely divided incandescent particles of solid carbon that are present because the oxygen in the primary mixture is insufficient to carry the oxidation of all the carbon of the hydrocarbons in the fuel gas as far as carbon monoxide. Another limit to satisfactory operation is also encountered in the Meker type of burner where the burner head is composed of a number of closely spaced ports. In this type of construction, no secondary air reaches the vicinity of the inner ports. Secondary combustion is an important factor in preventing the "lifting" of the primary flame. As the primary air is reduced on 
a burner of this type, a point is reached at which the inner cones begin to lift off the individual small ports and merge into larger and longer inner cones. A flame of this kind is much less effective for most purposes for which the Meker burner is used. This condition will be referred to in what follows as a smothering limit and is reached on the Mekertype burner at higher primary air rates than the yellow tip limit. Lifting, flash-back, yellow-tip, and smothering of the flames are all conditions that prevent the proper application of heat. Lifting, flash-back, and smothering may result in the escape of unburned gas and carbon monoxide, whereas a yellow-tip condition causes a carbon deposit on the material being heated, and may also be accompanied by incomplete combustion. All four of these conditions result in a loss of heat. It therefore follows that a satisfactory laboratory burner is one that is capable of operating within these limits over the entire range of gas rates required.

\section{Method Used for Determining Limits of Burner Operation}

In order to determine the conditions under which the limits of operation are found, each burner was installed so that both the gas rate and the supply of primary air could be varied as desired, and the rates of flow of each could be accurately determined. Figure 3 shows the appa- ratus used for these tests. ${ }^{2}$ With a burner installed in such an apparatus and burning gas at a constant rate, the primary air was increased until the flames either lifted from the ports or flashed back into the burner. When this condition was obtained, the proportion of air in the primary mixture was determined. The primary air was next decreased until yellow appeared in the flame, and the proportion of air in the primary mixture was again determined. When testing each of the Meker burners another setting of primary air was made, so that the inner flame cones were no longer stable on the individual ports and were beginning to merge and elongate. The ratio of primary air to gas where this condition was obtained was also determined. The gas-rate was then changed and the same procedure repeated. This process was continued until a series of tests had been made that covered the desired range of gas rates or until the points obtained indicated that other rates could not be used because they fell outside the limits of operation. The results obtained were plotted, using as the coordinates, "gas rate: thousands of Btu per hour" and "primary air: percentage of the total air required."

Figure 4 represents the position of the boundaries of the regions in which lifting, smothering, and yellow-tips were obtained with Burner 1, a Meker-type burner. The small circles with short lines pointing upward represent conditions under

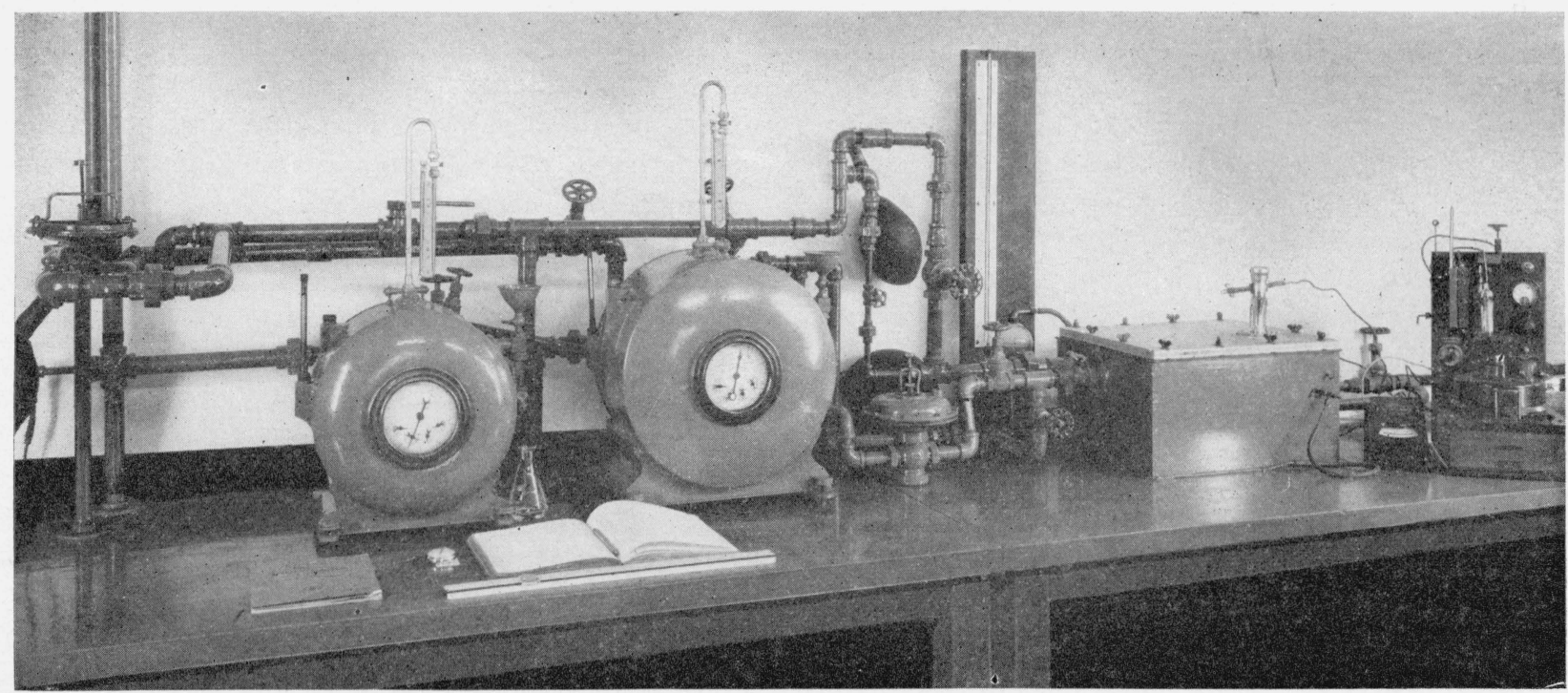

Figure 3. Apparatus used to study the performance of gas burners. 


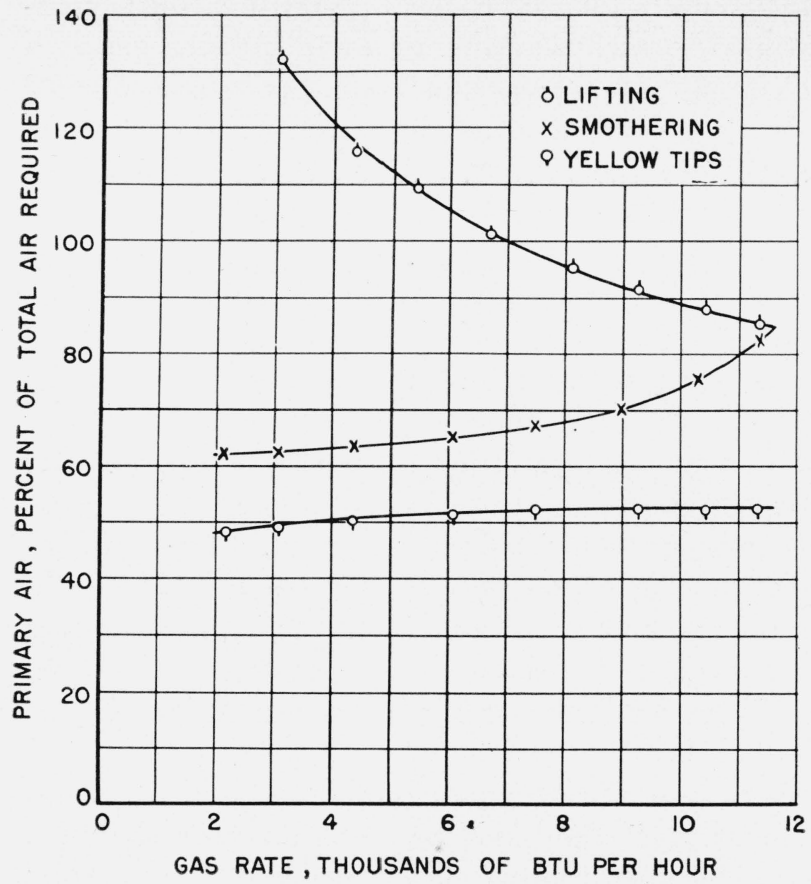

Figure 4. Boundaries of the regions in which lifting, smothering, and yellow-tips occur with burner 1.

which the flames were observed to lift; those with the short lines pointing downward represent conditions under which yellow-tips first appeared in the flames; and the crosses represent conditions under which smothering of the inner flames occurred. As mentioned previously, flash-back is not usually encountered with the average burner with natural gas and was not found to be a limiting condition with any of the laboratory burners tested.

Any adjustment of primary air which falls above the lifting curve or below the smothering curve will produce an unstable or unsuitable flame, whereas any air adjustment that falls below the yellow tip curve will produce carbon and be otherwise unstatisfactory.

With the Meker-type burner it is therefore necessary to adjust the burner so that the primary air setting falls between the lifting and smothering curves. In the case of a single-port burner, there is no smothering limit so that the adjustment is made between the lifting and yellow-tip limits. It will be observed that the lifting curve and the smothering curve obtained with burner 1 intersect at a gas rate of $11,600 \mathrm{Btu} / \mathrm{hr}$. This rate is, therefore, the maximum that could be used without encountering one of these limits. A rate somewhat less than 11,600 would have to be used in order to obtain a primary air setting that would produce a stable flame.

Having located the position of the limits of operation of a burner, the next step is to determine how much of this stable range can actually be utilized when the burner is operated normally.

\section{Normal Air Injection}

In the determination of the limits of operation the orifice used was unimportant, because the primary air was forced into the burner. It was merely necessary to use a size that would allow the gas to pass at the desired rate under the range of gas pressures available. However, when an appliance is installed for use, the primary air is drawn into the burner by the energy of the gas stream issuing from the orifice, and the amount thus injected depends in part upon the size of the orifice. When using any given rate of gas supply the amount of air injected increases as the size of the orifice is decreased, higher pressures being necessary, however, to maintain the given rate. For the greatest range of usable gas rates it was therefore necessary to determine the largest orifice that could be used with each burner and still obtain an air injection that would produce a stable flame. For this determination the burner was connected to a source of gas supply only, the air-mixer being left open to the air of the room. When an air shutter was provided, it was set in its wide open position. If the burner was supplied with an adjustable orifice, it was set by means of the needle so that the maximum gas rate possible was obtained without encountering any of the limiting conditions. This setting was made at the highest gas line pressure available, which in these tests was 6 in. of water pressure. If the burner was supplied with a fixed orifice, several different sizes were tried until the one was found that would allow the highest gas rate with a stable flame. Once this condition was found, the proportion of air in the primary mixture within the burner head and the gas rate were determined. Without any further change in orifice adjustment, other points on the normal injection were found by varying the line pressure. These points were then added to the plot showing the limiting curves. 


\section{Results Obtained with Meker-Type Burners}

Figure 5 shows the complete results obtained on burner 1 . The limiting curves showing the position of lifting, smothering, and yellow-tips are the same as given on figure 4, but two normal air injection curves have been added. One of these was obtained with an orifice of No. 54 drill size (0.0023-in. ${ }^{2}$ area) and the other with a No. 56 $\left(0.0017\right.$-in. ${ }^{2}$ area). The normal air injection obtained with the No. 54 orifice is below the smothering curve at all rates. A No. 54 orifice is therefore too large to give a stable flame with this burner. The curve obtained with the No. 56 orifice is above the smothering curve at all pressures and its use results in a stable flame. A No. 55 orifice (curve not shown) gave results intermediate between the No. 54 and No. 56 , but the injection was below the smothering curve at the 6 -in. pressure. It is therefore apparent that a No. 56 orifice is the largest size that can be used with this burner, and since the maximum line pressure available in our laboratory is $6 \mathrm{in}$. of water, it is not possible to obtain a stable flame above a rate of $7,500 \mathrm{Btu} . / \mathrm{hr}$. This condition is typical of all burners of the Meker type tested.

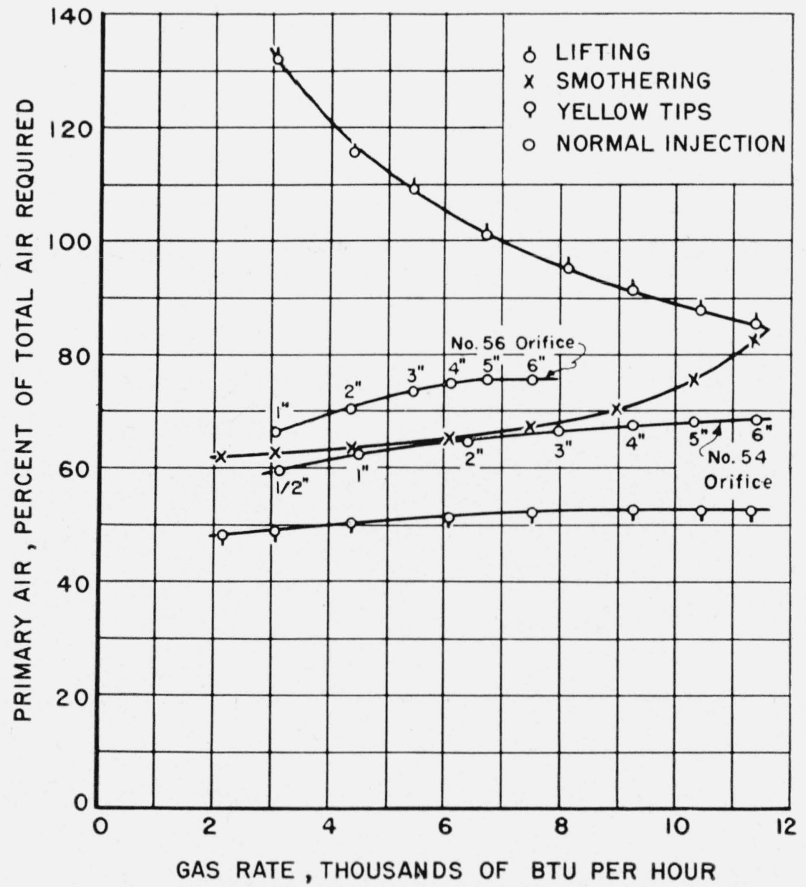

Figure 5. Combined curves showing the limits of operation and normal air injection with Meker burner 1 .
Considering only the lifting and smothering limits, it should be possible to use this burner at gas rates up to $11,000 \mathrm{Btu} / \mathrm{hr}$. (maximum stable gas rate 11,600$)$, but to do so would require a primary air injection of between 80 and 86 percent. To obtain such an air entrainment would require the use of a No. 58 orifice, and with this smaller size the 6 -in. pressure available would deliver only about $6,200 \mathrm{Btu} / \mathrm{hr}$. This burner would have to be modified so that higher air injections are possible with a No. 54 orifice, or pressures up to $13 \mathrm{in}$. of water would be needed to use this burner with the No. 56 orifice at a rate of 11,000 $\mathrm{Btu} / \mathrm{hr}$.

Curves similar to those shown in figure 5 were determined and plotted for each of the seven other Meker-type burners. From these curves the maximum stable gas rate determined by the limiting curves only and the maximum stable gas rate obtainable under normal operating conditions were determined in the manner just described and are shown in table 2 .

TABLE 2. Comparison of maximum theoretical gas rate and highest stable rates obtainable with the Meker burners

\begin{tabular}{|c|c|c|}
\hline Burner number & $\begin{array}{l}\text { Maximum stable } \\
\text { gas rate deter- } \\
\text { mined by limit- } \\
\text { ing curves }\end{array}$ & $\begin{array}{l}\text { Maximum stable } \\
\text { gas rate obtain- } \\
\text { able under nor- } \\
\text { mal operating } \\
\text { conditions }\end{array}$ \\
\hline & $B t u / h r$ & $B t u / h r$ \\
\hline $1 \ldots$ & 11,600 & 7,500 \\
\hline $2 \ldots \ldots$ & 6,500 & 3,880 \\
\hline $3 \ldots . .$. & 10,500 & 5,680 \\
\hline $4 \ldots \ldots$ & 11,000 & 7,350 \\
\hline $6 \ldots$ & 12,000 & 8,200 \\
\hline $8 \ldots$ & 6,850 & 4,930 \\
\hline 9 & 29,000 & 16,150 \\
\hline 15 & 17,500 & 7,000 \\
\hline
\end{tabular}

In each case the maximum stable gas rate as determined by normal operation is much less than the rate that could be obtained, provided it was possible to obtain higher air injections with an orifice capable of passing these higher rates.

Except for burner 9, which is considerably larger than any of the other burners, the highest usable gas rate is $8,200 \mathrm{Btu} / \mathrm{hr}$. This rate is sufficient for many heating operations but is not high enough for all. We believe these burners should be capable of giving stable flames up to at least $10,000 \mathrm{Btu} / \mathrm{hr}$ in order to cover the range of Btu rates required for normal laboratory work. 


\section{Results Obtained with Straight-Tube Burners}

The burners shown in figure 2 are all classed as straight-tube burners. Limiting curves were obtained with each of these burners in a manner similar to that used for the eight Meker types, except that with these burners there is no smothering limit. Figure 6 shows the position of the lifting and yellow-tip limits and the normal air injection with burner 5. This burner has a fixed

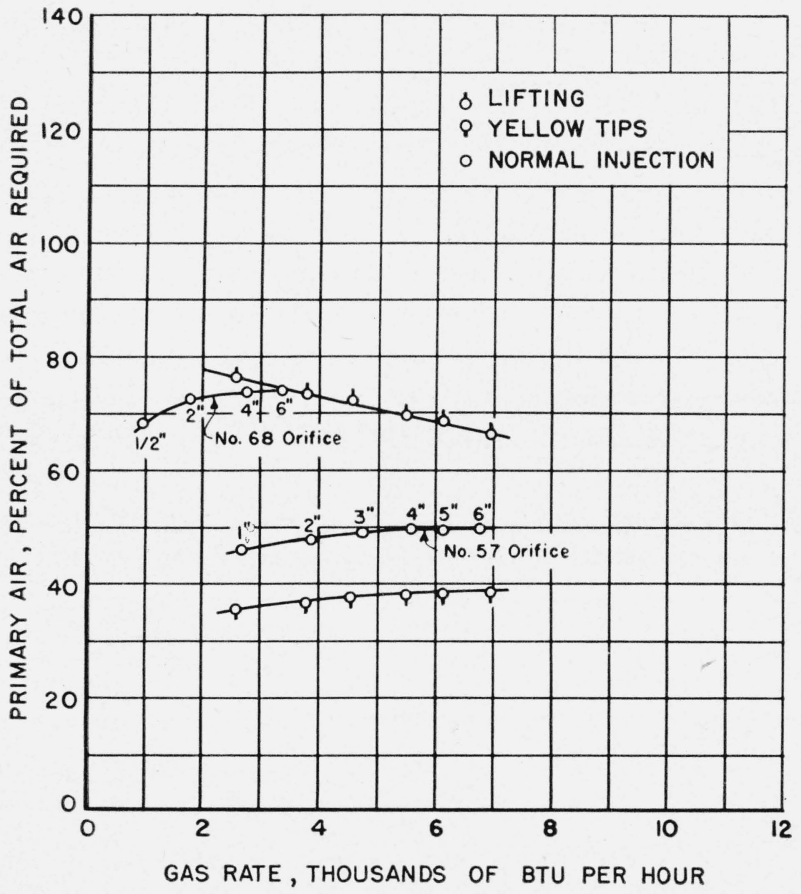

Figure 6. Combined curves showing the limits of operation and normal air injection with stright-tube burner 5 .

orifice of a No. 57 drill size (0.00145-in. ${ }^{2}$ area). The highest gas rate that is possible with this orifice and the maximum 6-in. line pressure is $6,720 \mathrm{Btu} / \mathrm{hr}$, and the air injection obtained was 50 percent of the total air required for complete combustion. The flame produced was stable and fell within the limits of lifting and yellow tips but was soft in appearance and was suitable for few heating applications.

On most domestic appliances it is rarely desirable to produce very high temperatures of the objects heated, and the intensity of the flame is usually unimportant. Any condition of operation that results in complete combustion between the limits of lifting and yellow-tips is nearly equally satisfactory. In contrast, since laboratory burners are used for igniting crucibles and other purposes for which intense flames are needed to produce high temperatures, the highest percentage of primary air practicable without causing lifting is desired. At least 70 percent of primary air should be obtainable. In order to obtain such an air entrainment with this burner, it was necessary to reduce the size of the orifice to a No. 68 drill. This resulted in an air injection of 74 percent but reduced the maximum gas rate obtainable at the 6 -in. pressure to $3,360 \mathrm{Btu} / \mathrm{hr}$. We believe it would be desirable for burners of this type to be capable of producing a hard well-defined flame at rates up to at least $5,000 \mathrm{Btu} / \mathrm{hr}$. A study of figure 6 indicates that a rate of $5,000 \mathrm{Btu} /$ $\mathrm{hr}$, with a 70-percent air injection would be a stable setting, since this adjustment falls below the lifting curve. Actually the maximum rate at a 70-percent air injection would be the intersection of the 70-percent air line with the lifting curve that occurs with this burner at a rate of 5,300 $\mathrm{Btu} / \mathrm{hr}$. The air injecting power of this burner is not sufficient, however, to obtain a 70-percent injection with an orifice capable of giving a rate of $5,300 \mathrm{Btu} / \mathrm{hr}$ with the 6 -in. gas pressure available. It"is evident that this burner needs some modification in order to accomplish such a result with natural gas.

Table 3 shows the maximum stable rate for each of the straight-tube burners tested. This rate was determined from the curves obtained with each burner by noting the intersection of the 70-percent air line with the lifting curve. The highest rate obtainable with each burner when operated normally is also shown. This was

TABLE 3. Comparison of maximum theoretical gas rate and highest stable rates obtainable with the straight-tube burners

\begin{tabular}{|c|c|c|}
\hline Burner number & $\begin{array}{l}\text { Maximum stable } \\
\text { gas rate deter- } \\
\text { mined by inter- } \\
\text { section of lifting } \\
\text { curve and } 70- \\
\text { percent air line }\end{array}$ & $\begin{array}{l}\text { Maximum stable } \\
\text { gas rate obtain- } \\
\text { able under nor- } \\
\text { mal operating } \\
\text { conditions with } \\
\text { 70-percent air in- } \\
\text { jection }\end{array}$ \\
\hline & $B t u / h r$ & $B t u / h r$ \\
\hline $5 \ldots \ldots$ & 5,300 & 3,360 \\
\hline $7 \ldots$ & 7,500 & 2,448 \\
\hline $10 \ldots$ & 4,450 & 2,066 \\
\hline $11 \ldots$ & 13,900 & 1,680 \\
\hline $14 \ldots$ & 23,000 & 4,000 \\
\hline $16 \ldots \ldots$ & 5,100 & 1,586 \\
\hline $17 \ldots \ldots$ & 7,900 & 4,331 \\
\hline $18 \ldots \ldots$ & 12,500 & 10,667 \\
\hline
\end{tabular}


obtained by determining the gas rate delivered at a 6 -in. pressure when using an orifice that would give at least a 70-percent air injection.

This table shows that all of the burners with the exception of 18 give usable rates below 5,000 $\mathrm{Btu} / \mathrm{hr}$ on natural gas. Burner 18 is a larger burner than the others, and according to the data in the manufacturer's catalog should be capable of operating at a rate of $13,000 \mathrm{Btu} / \mathrm{hr}$.

This shows that the average. straight-tube burner, like the Meker burner, must be redesigned if a range of usable rates higher than can now be obtained is required.

\section{Basic Data for Burner Design}

Research conducted on domestic atmospheric burners has shown that if optimum performance of the burner is to be obtained certain dimensional relationships must be adhered to.

Those factors that are of importance to the operation of a laboratory burner are discussed below.

1. Port area.-Previous work has shown that there is a definite relation between the port area and the maximum rate at which gas can be burned. It is also known that the maximum rate per square inch of port area is different for gases of different composition. For example, the port area required to burn natural gas at a definite Btu rate is greater than for manufactured gas because of the greater tendency of the natural gas flames to lift. Consequently, if the same burner were used on both gases without any change of port area, it would not be possible to obtain a stable flame with natural gas at as high a Btu rate as could be obtained with one of the manufactured gases. This variation in rate for equal flame stability is indicated by the following figures, which were determined in studies of range burners.

TABLE 4. Maximum Btu per square inch of port area for gases of different composition

Data determined on gas range burners. All determined at 70-percent air injection

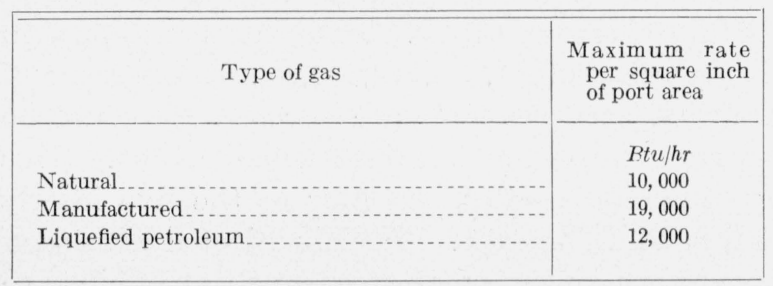

However, port area and gas composition are not the only factors that determine the position of the limiting curves of a burner. Two burners may have the same total port area but one may have a single opening, as is the case with a straighttube burner; the other may have a number of smaller ports. These two burners would not have the same limits of operation and would therefore not be likely to have the same limit of usable gas rate. The heat transfer from the burner tube to the gas mixture, the uniformity of mixing of the air and gas within the burner, and the spacing of the ports are also conditions that influence the position of the limits of operation. All of the range burners used in determining the maximum rates given above were similar in design, whereas the 16 laboratory burners used in this study have wide differences in their construction. Because of this variation in design there is no certainty that the same relation between port area and rate would be obtained as with the range burners nor that the various laboratory burners would all give the same result. One of the Meker burners was supplied with three heads of different size, having port areas of $0.54,1.02$, and 2.07 in. $^{2}$ respectively. Limiting curves were determined for each of these burner heads, and the maximum

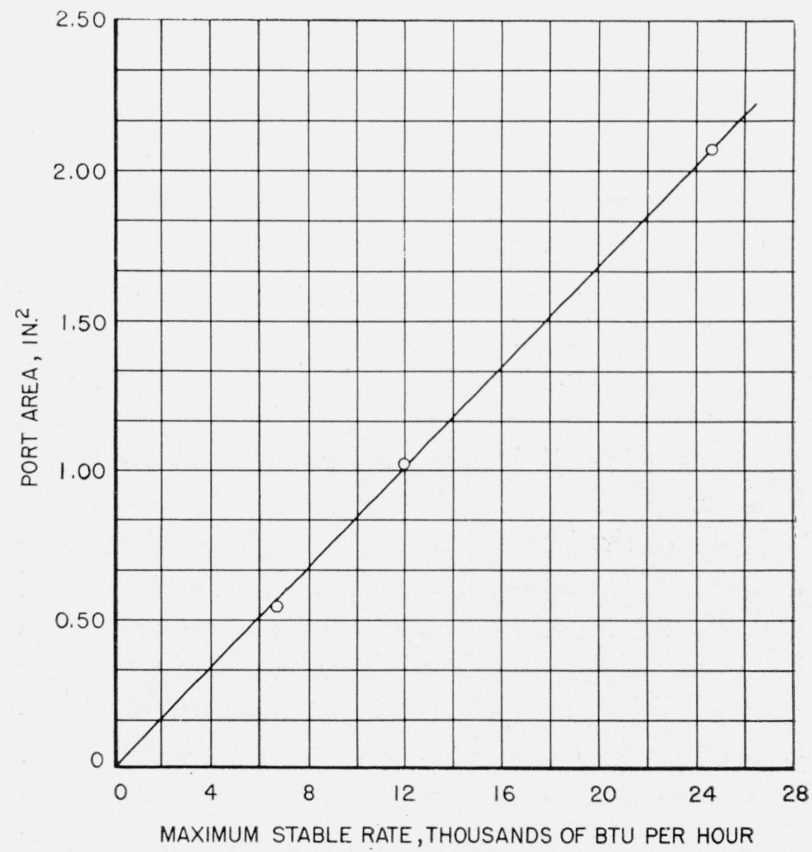

Figure 7. Variation in maximum stable gas rate with change in port area.

Curve determined with burner 6 . 
stable rates were determined for each by the intersection of the lifting and smothering curves. These three rates were then plotted against the corresponding port area and give the curve shown in figure 7. This curve gives a straight-line relationship between the port area and the maximum stable rate and indicates that this burner should be capable of burning $12,000 \mathrm{Btu} / \mathrm{hr}$ per square inch of port area. Assuming that data of a similar nature, if it could have been determined on the other Meker burners, would have also given straight lines, the results on the other seven burners were calculated to a basis of 1 in. ${ }^{2}$ of port area with the results shown in table 5 . It is evident that the maximum rates calculated for these burners, all based on 1 in. ${ }^{2}$ of port area, show considerable variation.

TABLE 5. Maximum theoretical gas rate per 1 square inch of port area

Data calculated for eight Meker burners

\begin{tabular}{|c|c|}
\hline Burner number & $\begin{array}{l}\text { Computed maxi- } \\
\text { mum stable gas } \\
\text { rate per sq in of } \\
\text { port area }\end{array}$ \\
\hline & $B t u / h r$ \\
\hline 1 & 15,000 \\
\hline $2 \ldots$ & 9,450 \\
\hline 3 & 15,850 \\
\hline 4 & 18,700 \\
\hline 6 & 11,800 \\
\hline 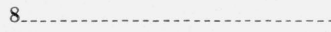 & 27,000 \\
\hline 9 & 25,100 \\
\hline 15 & 25,500 \\
\hline
\end{tabular}

If the relationship shown above is also applicable to the laboratory burner, then the Meker burner should have a 1-in. ${ }^{2}$ port area for the rate of 10,000 $\mathrm{Btu} / \mathrm{hr}$ previously assumed to be necessary, and the straight-tube burners should have a port area not less than $\frac{1}{2}$ in. $^{2}$ in order to produce 5,000 $\mathrm{Btu} / \mathrm{hr}$.

None of the burners tested could be used at rates as high as the limit set by lifting and smothering. On the average, the maximum usable gas rates with the eight Meker burners were limited by poor air injection to about 60 percent of the maximum rate as determined by the limiting curves. This is because normal operation depends on factors in the design of the burner that do not enter into the determination of the limiting curves. Such conditions as the shape of the mixing-tube, the type and position of the orifice, and the provi- sion for entrance of primary air all affect the air injection that can be obtained and therefore have a part in determining the maximum usable gas rate.

An average of the results shown in table 5, exclusive of burner 9 , gives a rate of $17,614 \mathrm{Btu} / \mathrm{hr}$. Sixty percent of this is a rate of $10,568 \mathrm{Btu} / \mathrm{hr}$. It therefore seems reasonable to assume that a Meker burner properly proportioned should be capable of burning gas at the rate of at least $10,000 \mathrm{Btu} / \mathrm{hr}$ per square inch of port area.

Treating the data obtained on the straight-tube burners in a somewhat similar manner, the results indicate that a burner having a port area of $0.1 \mathrm{in} .^{2}$ should allow a rate of $3,350 \mathrm{Btu} / \mathrm{hr}$. In order to burn gas at a rate of $5,000 \mathrm{Btu} / \mathrm{hr}$ it would be necessary to use a port area of 0.15 in. $^{2}$ or a tube of at least $7 / 16$-in. inside diameter. Only one of the eight straight-tube burners has a port area as large as this. Burner 18 has a port area of 0.296 in. $^{2}$ and should be capable of burning gas at a rate of approximately $10,000 \mathrm{Btu} / \mathrm{hr}$ if figured on this same basis. The maximum usable rate with burner 18 was $10,667 \mathrm{Btu} / \mathrm{hr}$.

2. Throat area.-In order to obtain maximum air injection with a Meker-type burner it is necessary to constrict the mixing-tube at a point just beyond that at which the primary air enters. This constriction, or venturi, increases the velocity of the gas-air mixture passing this point, which in turn increases the suction that draws air into the burner at the primary air openings. It has been determined that a ratio between this throat area and the port area of 40 percent gives the highest air entrainment. This ratio is not too critical but should be held between 35 and 45 percent. Since this relationship was determined on work with domestic burners, it seemed desirable to verify it for a laboratory-type burner. For this work a straight tube was obtained that would fit the burner top having a port area of 2.07 in. $^{2}$ The lower end of this tube was made to fit one of the burner bases and provided with sufficient primary air openings so that when the air shutter was wide open there was ample area for the entrance of air. Five brass inserts with throat areas of $20,30,40,60$, and 83 percent of the port area were made so that they could be inserted into the straight mixing-tube. This experimental burner and four of the five inserts are shown in figure 8 . The air injected with each of these five inserts was determined at a 6 -in. line 


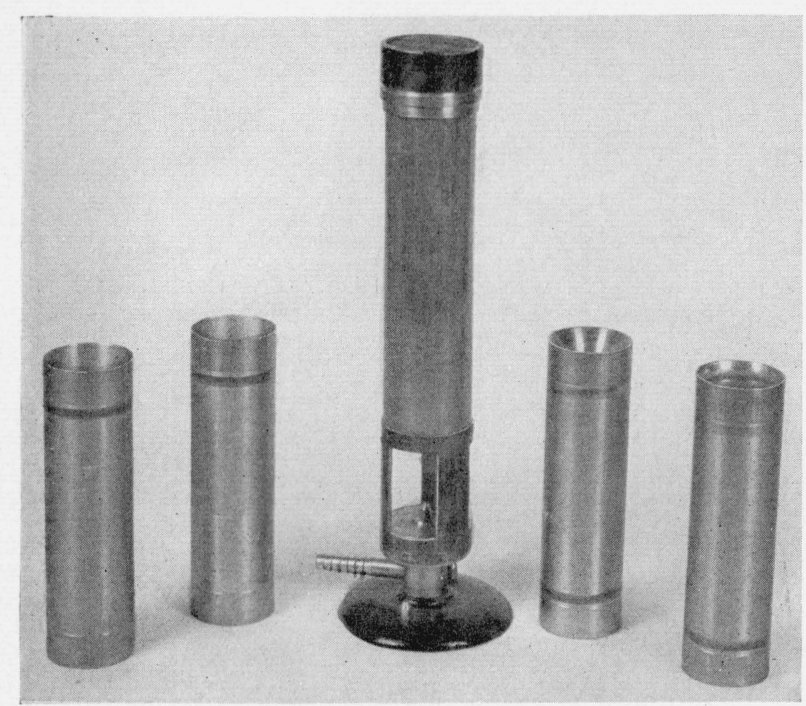

FiguRE 8. Experimental burner used for checking fundamental relations on laboratory type burners.

pressure for each of five different sized orifices. Two series of tests were made; one with the gas burning or the burner hot, and one with the gas unlighted or the burner at room temperature. The room-temperature tests had the advantage of being able to cover a greater range of gas rates without being limited by lifting and flash back. The air injection obtained with the burner cold was higher than when the burner was hot, but both series indicated that with a burner of the

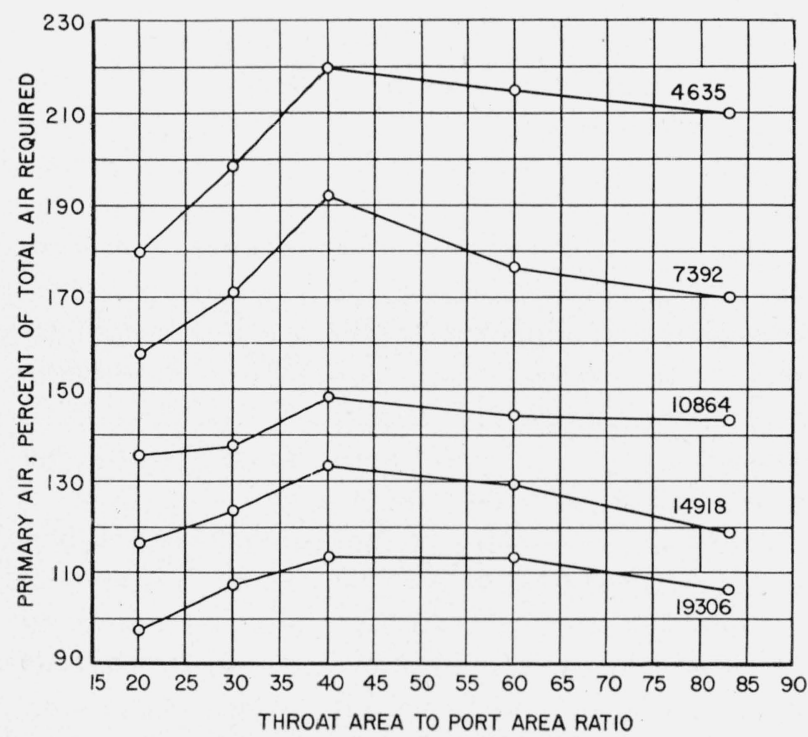

Figure 9. Comparison of air injected with various ratios between throat and port area.

Numbers on curves indicate Btu/hr.
Meker type the 40-percent throat gives the highest air injection. The results determined with the burner at room temperature are shown in figure 9 . These curves also verify the previous findings that small variations from a 40 -percent ratio of throat to port area have a small effect upon the air injected, although the change in air injection becomes more pronounced as the gas rate is decreased.

For the Meker-type burner it therefore follows that the throat area should be approximately 40 percent of the port area in order to obtain the highest air injection with whatever orifice size is used. That this optimum relationship is not followed in all of these burners is apparent from the following table.

TABLE 6. Ratio between throat and port area for 8 Meker burners tested

\begin{tabular}{|c|c|}
\hline Burner number & $\begin{array}{l}\text { Throat area as } \\
\text { percentage of } \\
\text { port area }\end{array}$ \\
\hline 1 & 42.9 \\
\hline 2 & 46.8 \\
\hline 3 & 25.1 \\
\hline 4 & 29.5 \\
\hline 6 & 29.6 \\
\hline 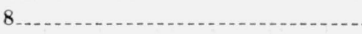 & 120.7 \\
\hline 9 & 51.4 \\
\hline 15 & 16.8 \\
\hline
\end{tabular}

The straight-tube burners have no venturi throat and studies of air entrainment in straight tubes [4] have shown that for this type of burner a venturi does not increase the amount of air entrained.

3. Primary air opening.-Work conducted by the American Gas Association Testing Laboratories on the amount of opening that should be provided for the admittance of primary air resulted in the conclusion that the minimum opening should be 1.25 times the total port area for burners that would operate normally at less than 70-percent air entrainment. For primary air injection greater than 70 percent, an opening of 2.25 times the total port area is recommended. It seemed desirable to verify these results on the laboratory-type burner. For this purpose the experimental burner with the 40 -percent throat was used. Gas at 6-in. pressure was supplied to the burner at a constant rate through one of a series of fixed orifices, and air injection tests were made at various known primary air openings 
starting with the air shutter wide open and decreasing this opening by small increments until a definite decrease in air injection was observed. Similar tests were made at other gas rates by substituting other orifices until a sufficient range of rates was covered. These results are shown in figure 10 , in which the primary air injected is

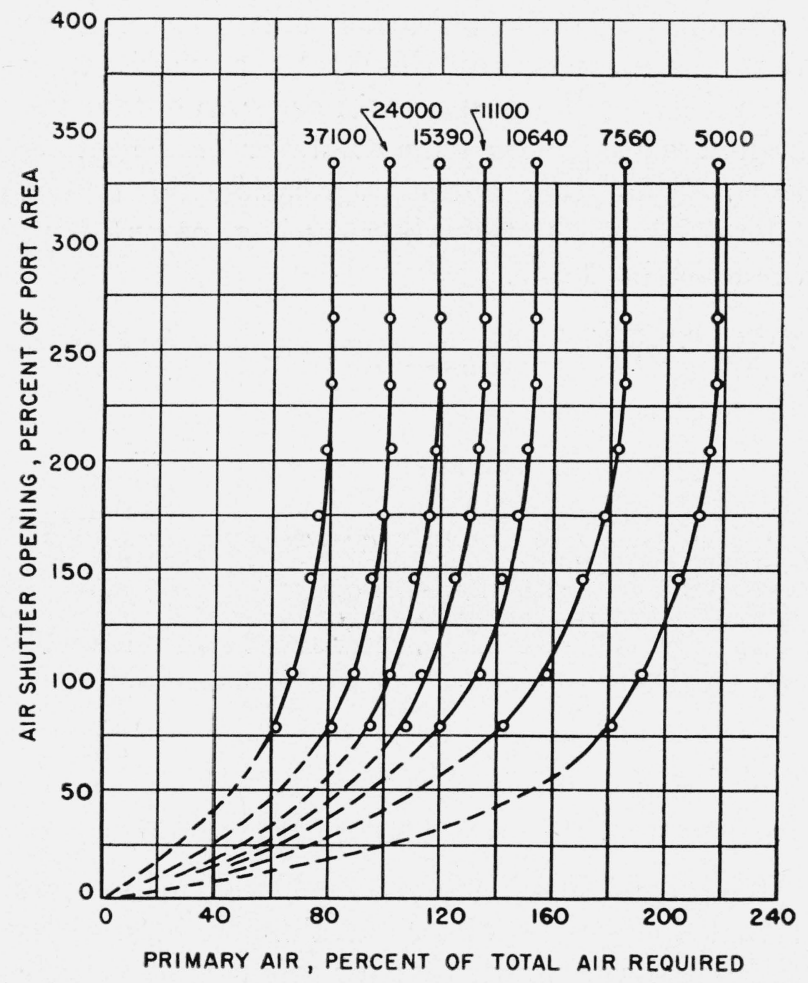

FIgURE 10. Effect of air shutter opening on primary air injected.

Numbers on curves indicate $\mathrm{Btu} / \mathrm{hr}$.

plotted against the air-shutter opening in percentage of port area. These data verify the American Gas Association figure and indicate that the primary air opening should be at least 2.25 times the port area. Any decrease below 2.25 reduces the maximum air that can be injected by the burner regardless of the gas rate used. Table 7 shows the ratio between the primary air opening and the port area for the 16 burners tested.

Only five of these burners have a sufficient opening for primary air if we consider a ratio of 2.25 as the minimum that should be provided. In fact, the lack of adequate air opening alone is sufficient to account for the poor showing of some of these burners.

4. Distance between throat and gas orifice.-
TABLE 7. Ratio between the primary air opening and the port area for the 16 burners tested

\begin{tabular}{|c|c|}
\hline Burner number & Ratio: $\frac{\text { primary air opening }}{\text { port area }}$ \\
\hline $1 \ldots \ldots$ & 1.42 \\
\hline 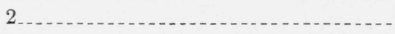 & 0.59 \\
\hline 3 & 1.17 \\
\hline 4 & 1.10 \\
\hline 5 & 2.98 \\
\hline 6 & 0.92 \\
\hline 7 7 & 1.47 \\
\hline 8 & 3.18 \\
\hline 9 & 1.18 \\
\hline 10 & 1.77 \\
\hline 11 & 2. 49 \\
\hline 14 & 3.33 \\
\hline 15 & 0.59 \\
\hline 16 & 1.44 \\
\hline 17 & 3. 26 \\
\hline 18 & 2. 11 \\
\hline
\end{tabular}

Studies by the gas utilization laboratory at this Bureau and other investigators show that it is necessary to place the orifice at a correct distance from the throat of the burner if optimum air injection is to be obtained. A decrease in air entrainment results if the orifice is either too far away or too close to the throat. The present studies indicate that the best results are obtained if the orifice is located about two throat-diameters away from the throat. Results observed by other laboratories show optimum conditions to be obtained between 0.5 and 2.0 throat-diameters away, depending upon the size of the throat used. For laboratory-type burners the distance should be kept between 1.0 and 2.5 throat-diameters. It is also necessary to have the orifice properly centered with respect to the mixing-tube. If the stream of gas is directed toward the walls rather than the center of the mixing-tube, the air entrainment is greatly reduced. Proper centering and also proper drilling of the orifice are therefore essential. Of equal importance, in this connection, is the travel of the needle in an adjustable orifice. It should be accurately centered with respect to the orifice from the fully open to the completely closed position.

5. Length and shape of the mixing-tube.-When a gas under pressure issues from an orifice, the momentum of the gas causes the surrounding air to be set in motion in the direction of the gas stream. Because of the velocity of this gas stream, eddy currents are set up in the surrounding air. The principal function of the mixing-tube is to complete the mixing process as rapidly as possible, 
permit the turbulence to die out, and to supply the burner ports with a uniform mixture of air and gas. The length and taper of the mixer beyond the throat should be such that the air-gas mixture expands gradually without sharp changes in diameter or direction that would maintain or produce turbulence until the "velocity head" at the throat has been largely converted into a "pressure head." The length of the mixing-tube should be at least six times the throat-diameter. The outlet from the throat should increase gradually, and the inlet for primary air should be such that the change in direction of flow of primary air is as gradual as possible. The best results are also obtained if the inside of the burner is smooth. Sharp changes in direction and roughness increase resistance to flow and result in a lower injection of primary air. Additional length of the mixingtube beyond six throat-diameters may be used, but the resistance to flow also increases as the length increases; and this will cause a reduction in primary injection if carried too far.

6. Burner temperature.-A cool burner has a higher air injection than a hot one, other things remaining equal. It is therefore advantageous to build the burner so that the heat is dissipated to the room rather than to the mixture of air and gas passing through the burner. A burner having a head temperature of $500^{\circ} \mathrm{F}$ has an air injection from 2 to 8 percent less than that of the same burner operated at room temperature. It has been shown that temperature causes a greater reduction in primary air injection in burners having long- or small-diameter mixing-tubes than in those having greater diameters or shorter tube lengths. It is also desirable to keep the weight of the metal used at a minimum.

It is believed the use of radiating fins on the Meker-type burners would tend to reduce the over-all temperature and thus increase the air entrained. On these burners, when adjusted for a sharp intense flame, the hottest part of the flame is very close to the metal of the burner head and results in a greater heating of the burner than is the case with the single-port burners.

\section{Results Obtained With Two Burners Modified to Comply With Basic Data}

To verify the accuracy of the relationships that appear to be required for the satisfactory opera- tion of a laboratory burner, 2 of the 16 burners were rebuilt to comply with these dimensions.

The port area of burner 16, a straight-tube burner, was increased from 0.13 to 0.15 in. $^{2}$ by drilling out the mixing-tube and flame retainer. The primary air opening was increased from 0.1816 to $0.3375 \mathrm{in.}^{2}$ (2.25 times the port area), and the orifice cap was plugged and redrilled with a No. 62 drill. When the burner was received from the manufacturer the orifice cap was drilled with a No. 51 drill, which delivered entirely too much gas when wide open. A No. 62 drill passes $5,000 \mathrm{Btu} / \mathrm{hr}$ at a 6 -in. pressure without the use of the needle. This results in a much higher air injection than was possible with the No. 51 orifice and still permits the needle to be used to obtain lower rates of gas flow.

The effect of these changes on the limits of operation and normal air injection is illustrated in figure 11. The curves marked by circles show

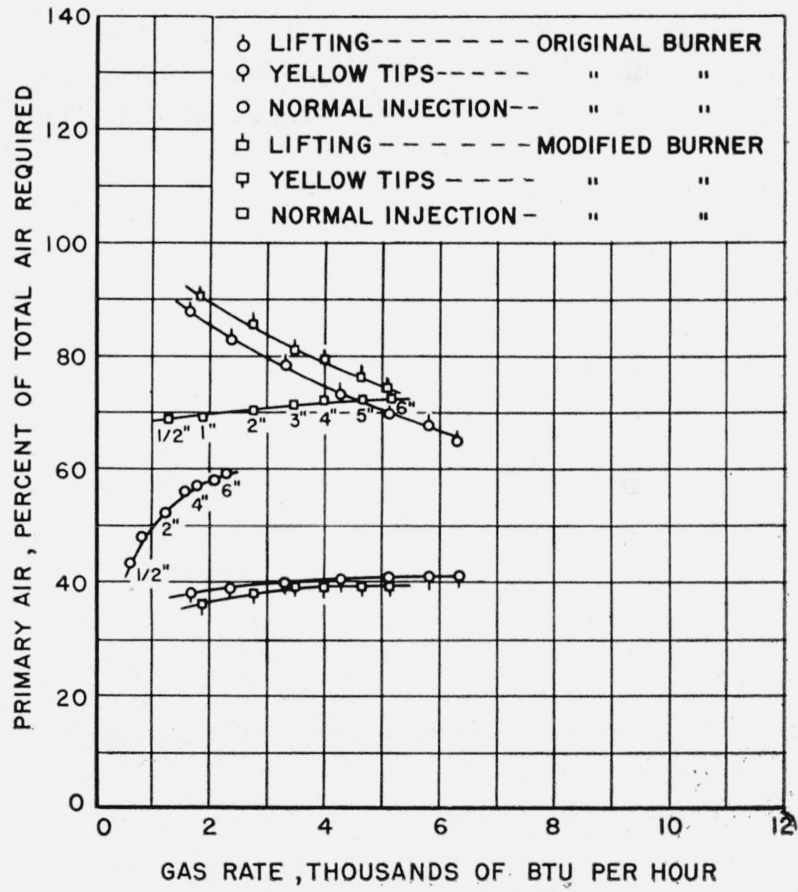

FIgURE 11. Effect on normal operation of rebuilding burner 16 to comply with basic requirements.

the normal air injection and limits of operation that were obtained with the burner as received. The highest rate that could be obtained and still inject sufficient air to give a reasonably hard flame was 2,260 Btu/hr. Even with this rate the highest air entrainment was only 59 percent, 
which is on the soft side. In order to obtain a 70-percent air entrainment it was necessary to reduce the rate to $1,586 \mathrm{Btu} / \mathrm{hr}$. It will be seen from the shape of this curve that the air entrained is reduced with each change of pressure below 6 in.

The curves marked with a square show the results obtained after the changes described above were made. With these modifications it is possible to obtain a primary air injection of more than 70 percent at any pressure above 1 in. of water, and the maximum gas rate is increased to 5,160 $\mathrm{Btu} / \mathrm{hr}$. It will also be observed that changes in pressure have little effect upon the air injection; the curve remains practically horizontal until pressures below 3 in. are used. Increasing the port area also improves the burner from the standpoint of both lifting and yellow tips as can be seen from the position of the two lifting and yellow-tip curves. It is therefore apparent that changing this burner so that the basic requirements are met not only improves the air injection but also increases the range of air entrainment within which the burner can operate without encountering a limiting condition. The modified burner can be satisfactorily operated at more than double the former usable gas rate. This is also illustrated in figure 12 , which shows the comparison between the flame produced on the modified burner and that obtained on a duplicate burner used as received from the manufacturer. Both burners are adjusted so that gas is being burned at a rate of $5,000 \mathrm{Btu} / \mathrm{hr}$. The flame on the modified burner is well aerated and hard in appearance while the flame on the burner on the left is soft in appearance and is not suitable for any operation where the application of intense heat is required.

Burner 6, a Meker type, was also changed so that its dimensions corresponded with the basic requirements. In this case the port area was not changed since it was already $1 \mathrm{in}^{2}$ The throat of this burner was too small, however, being only 29.6 percent of the port area, and the primary air opening was only 0.92 instead of 2.25 in. $^{2}$ A new mixing-tube with a 40-percent throat and an air opening of 2.25 in. $^{2}$ was made. A No. 55 fixed orifice, the size to pass $10,000 \mathrm{Btu} / \mathrm{hr}$ at a 6 -in. line pressure, was used. The results before and after these changes are shown in figure 13. The position of the limiting curves would remain the same, because no change was made that would affect either lifting, smothering, or the appearance of yellow-tips. The normal air-injection curve marked by circles was obtained with the burner as received and indicates that a No. 56 orifice is the largest size that can be used and still have a normal air injection that is in the stable region. The highest rate that could therefore be used with

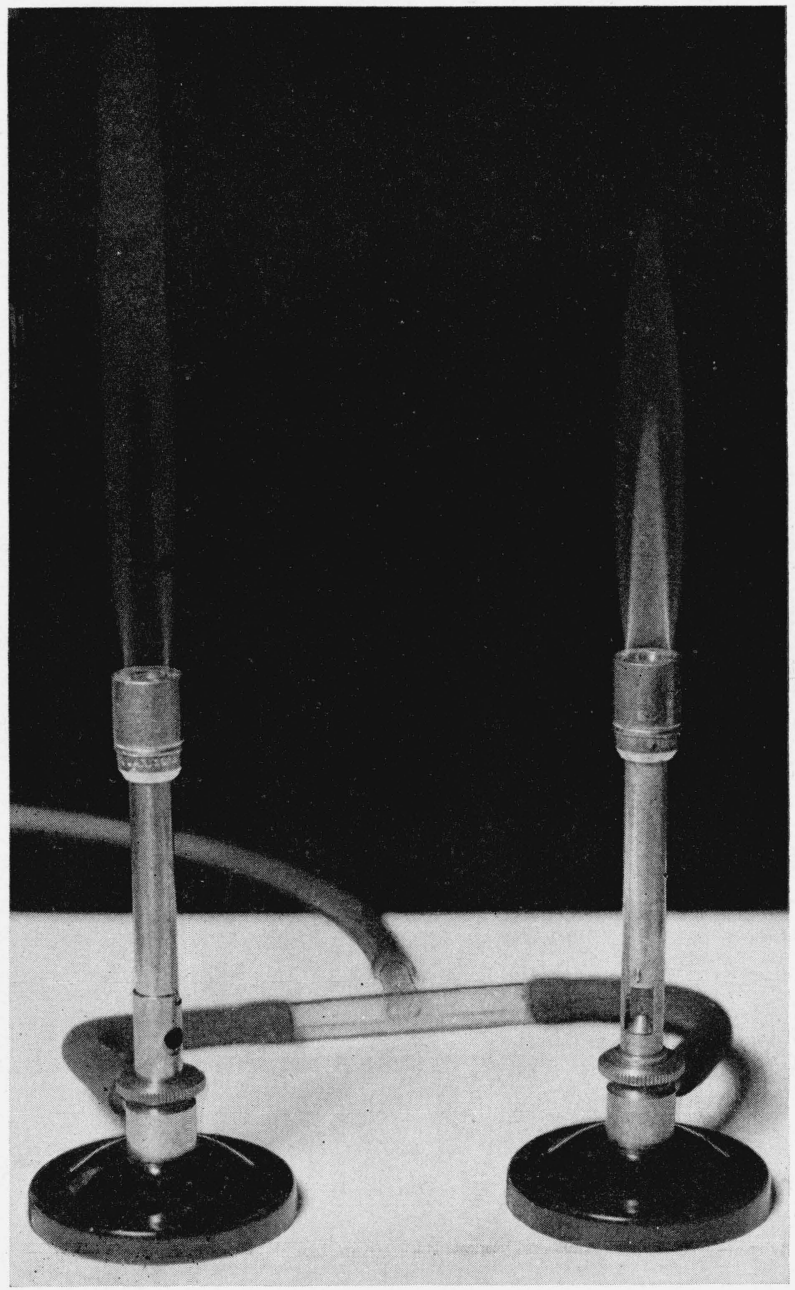

Figure 12. Comparison of flames produced by two similar burners, one as received and the other modified to meet basic requirements.

this burner was $8,200 \mathrm{Btu} / \mathrm{hr}$. The normal injection curve marked by squares shows the normal air injection obtained with a No. 55 orifice after the changes were made. This is a larger orifice and delivers $10,000 \mathrm{Btu} / \mathrm{hr}$ at a pressure of $6 \mathrm{in}$. It will also be observed that the air entrainment is higher than was obtained with the smaller orifice before the modifications were made. The flame produced is stable at all pressures, and the burner 


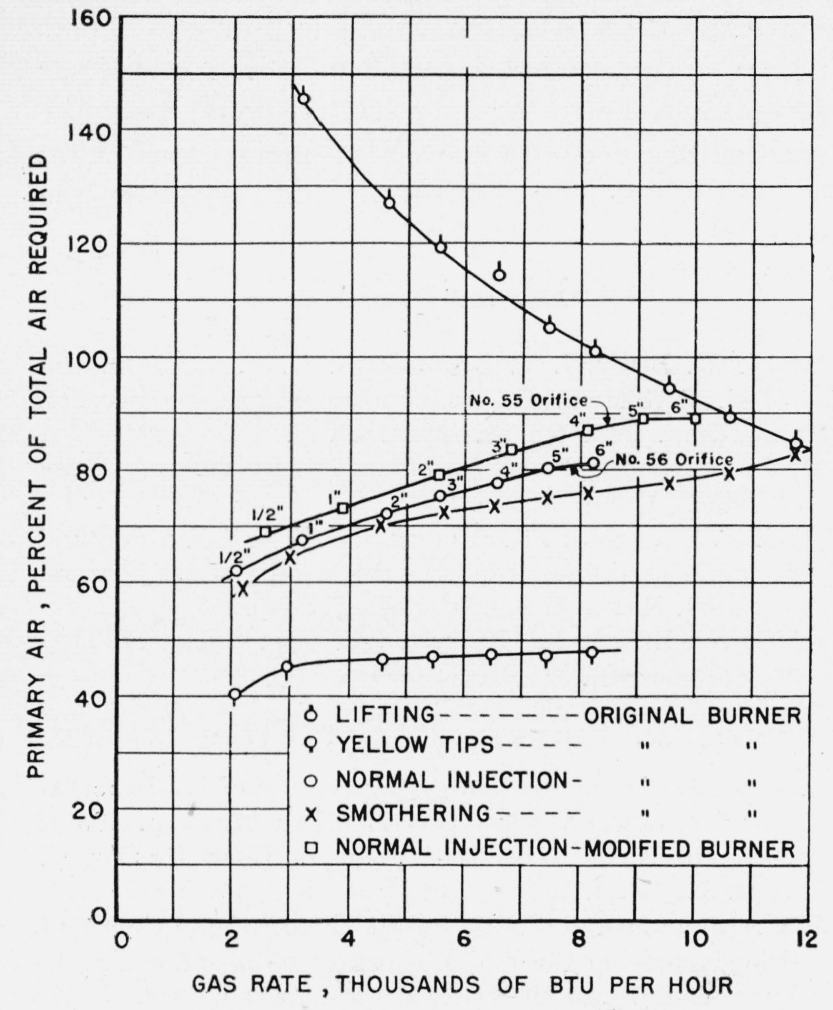

FIGURE 13. Effect on normal operation of rebuilding burner 6 to comply with basic requirements.

is now usable at a gas rate 22 percent above its former maximum.

This modified burner was also compared with a similar unmodified burner using propane as the fuel gas. Both burners were adjusted for the highest stable rate at a pressure of 11 in. of water.

The largest orifice that could be used with the unmodified burner was a No. 63, which gave 9,870 Btu/hr.

The modified burner having the proper throat size and primary air opening was capable of producing a stable flame with a No. 59 orifice, which delivers gas at the rate of $13,000 \mathrm{Btu} / \mathrm{hr}$.

\section{Summary}

Sixteen laboratory burners were included in this investigation, eight of the Meker and eight of the straight-tube type. Each burner was tested, and the limits within which it could be satisfactorily used were determined.

The average Meker burner could not be used at a rate above $6,363 \mathrm{Btu} / \mathrm{hr}$ on the natural gas distributed in Washington, D. C., whereas the average usable rate with the straight-tube burners was only $2,781 \mathrm{Btu} / \mathrm{hr}$. A survey of the various heating operations for which a laboratory burner is used indicated that the Meker-type burner should be capable of producing a hot stable flame up to $10,000 \mathrm{Btu} / \mathrm{hr}$, and the straight-tube burners should be usable at rates up to $5,000 \mathrm{Btu} / \mathrm{hr}$.

A comparison of the dimensions of these 16 burners with the fundamental relations for good burner operation brings out three major reasons for their unsatisfactory operation on natural gas.

(1) Too small a port area.-A Meker burner should have at least 1 in. ${ }^{2}$ of free port area in order to deliver as much as $10,000 \mathrm{Btu} / \mathrm{hr}$. A study of table 2 indicates that only two of the eight Meker burners tested were as large as 1 in. $^{2}$ From the results obtained on the straight-tube burners a port area of at least 0.15 in. $^{2}$ should be used if rates up to $5,000 \mathrm{Btu} / \mathrm{hr}$ are desired. Only one of the straight-tube burners had a port as large as 0.15 in. $^{2}$

(2) Improper throat size.-Results both from this study and those conducted by other investigators show the need of a throat having an area equal to 40 percent of the port area, if optimum air entrainment is to be obtained with a Mekertype burner. Most of these burners were unable to inject enough air to give a satisfactory flame with an orifice of adequate capacity. As shown by table 6 , only three of the Meker burners had throats close enough to the 40-percent requirement to approach optimum conditions.

(3) Insufficient primary air opening.-Figure 10 illustrates the need for an air opening equal to at least 2.25 times the port area in order to insure a sufficient opening for the entrance of primary air. A burner may be designed with sufficient port area and the proper venturi throat to inject a high percentage of primary air but be prevented from doing so because of too small an opening for the air to enter the mixing tube. Of the 16 burners tested, only 5 had a ratio of air shutter opening to port area as large as 2.25 .

In addition to the three factors given above, use of the proper orifice size is equally important. Some of the burners were equipped with adjustable orifices, which when used with the needle backed out gave entirely too high a gas rate for proper operation. By using the needle the rate could be reduced to the desired amount, but so much of the orifice was blocked by the needle 
when this condition was obtained that the air injection was impaired. It is much better to use an orifice size that will give the maximum rate desired when used in its wide open position and use the needle only to reduce the rate below this maximum. This will insure the maximum air entrainment from the standpoint of orifice size because the smaller the orifice the higher the percentage of air entrained. If a fixed orifice is used, it is obvious that the size should be the proper one for the maximum rate desired. In addition to the need for more care in the size of the orifices supplied with these burners, more attention should also be given to their assembly. The orifice should be centered with respect to the mixing tube and drilled so that the gas emerges in a vertical stream. The adjustable needles should also be accurately centered with respect to the orifice and stay centered as they are turned from one position to another.

The distance between the throat and the gas orifice, the length and shape of the mixing tube, and the temperature of the burner are all factors that affect the operation of a burner and should be given some consideration.

Two burners, one a straight-tube and the other a Meker type, were modified so that they complied with the basic requirements that appeared to be necessary from the results of our studies. These modified burners were retested and found to be greatly improved, both were capable of satisfactory operation over the range of gas rates desired.

It is believed that the use of these basic data by the manufacturers of laboratory burners would greatly improve this type of appliance and elim- inate the dissatisfaction which is now so evident where natural gas is distributed. A burner properly designed for natural gas should also give satisfactory performance with liquefied petroleum gases by merely substituting the proper orifice size.

\section{Reterences}

[1] W. M. Berry, I. V. Brumbaugh, G. F. Moulton, and G. B. Shawn, Design of atomspheric gas burners, Techn. Pap. BS 15, (1921) T193.

[2] F. A. Smith, Problems of stationary flames, Chem. Rev. 21, No. 3 (Dec. 1937).

[3] J. H. Eiseman, E. R. Weaver, and F. A. Smith, Method of determining most favorable design of gas burners, BS J. Research 8, 669 (1932) RP446.

[4] G. von Elbe and J. Brumer, Ind. Eng. Chem. 40, 1123 (June 1948).

Adpitional References Not Cited in Text

F. Wills, Design of gas burners by the use of fundamental flow formulas, Western Gas 7,87 to 99 (Aug. 1931); correction 7, 34 (Nov. 1931); (Pacific Coast Gas Assoc. Proc. 22, 1931).

J. H. Eiseman and F. A. Smith, Effect of the depth of drilled ports on the limits of operation of domestic gas burners, J. Research NBS 18, 485 (1937) RP988.

Flow of gas through orifices on domestic appliances, Bul. No. 1 (Am. Gas Assoc. Testing Lab.).

E. Buckingham and J. D. Edwards, Efflux of gases through small orifices, BS Sci. Pap. 15, 573 (1920) S359.

E. R. Weaver, J. H. Eiseman, and F. A. Smith, Gas burner design, Am. Gas J. 134, 54 to 56 (May 1931); 135, 35 to 38 (June 1931).

A. S. Leonard and E. D. Howe, Characteristics of natural gas flames, Proc. Pacific Coast Gas Assoc. 26 (1935).

Research in fundamentals of atmospheric gas burner design, Bul. No. 10 (Am. Gas Assoc. Testing Lab., 1940).

Washington, November 23, 1948. 